\section{The Impact of Metacognitive Mediation on 12-Year-Old Students' Self-Efficacy Beliefs for Performing Complex Tasks}

\author{
Stéphane Colognesia, ${ }^{a,}$, Vanessa Hanin ${ }^{b}$, Alena Stillc, Catherine Van \\ Nieuwenhoven ${ }^{\mathrm{d}}$
}

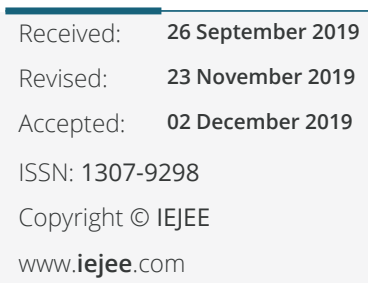

www.iejee.com

DOI: 10.26822/iejee.2019257657

\begin{abstract}
The goal of this study is to identify the links between metacognitive mediation and students' self-efficacy belief for the performance of complex tasks. We worked for three weeks with six human sciences classes of secondary 1 students who all performed the same tasks. In two classes, metacognition was initiated by the teacher, in two others, activation of metacognition occurred between peers and in the remaining two, there was no metacognitive mediation. Our goal is to compare the three conditions in terms of changes in students' self-efficacy belief through a pretest-posttest comparison among the 85 students who took part in the study. In addition, we interviewed four students in each condition where metacognition was used. The quantitative results showed that self-efficacy improved in classes where metacognition was introduced which was not the case in the classes where students did not receive any metacognitive prompting. In addition, the comparison of classes "with metacognition" showed that regardless of the agent (the teacher or peers), prompting of metacognition led to improvement in aspects related to active mastery experiences and psychological states of self-efficacy. The difference between these two conditions lay in the strategies available to students to succeed in the tasks.
\end{abstract}

Keywords: Metacognition, Metacognitive Mediation, Self-Efficacy Beliefs, Task

\section{Introduction}

Hattie's (2009) meta-analysis, which synthesized more than 800 studies on the influences on school-age students' academic performance, showed that among the 30 most important variables out of 138 affecting student achievement, the teaching of metacognitive strategies ranks 9th (after items such as formative assessment, goal setting, teacher clarity, adapting instruction to individual student needs/abilities, peer learning, feedback, teacher relationship, which are aspects coming from much research). This echoes the work on measures of effective teaching (Creemers 1999; Ko et al. 2014; Scheerens 2008) which explains that effective teachers teach metacognitive strategies to their students and give them the opportunity to master these strategies. The importance of metacognitive skills for success has been demonstrated in several studies: they lead students to greater autonomy, better memorization, conscious practice and better succeed in tasks (Lafortune et al. 2000) Furthermore, metacognition has been identified as a characteristic of effective learning (Kauffman 2004). In addition, metacognition also play a role in self-efficacy beliefs (Colognesi \& Van Nieuwenhoven, 2016; Hanin \& Van Nieuwenhoven, 2018), because such practices give students the opportunity to take a look at their work, at the development of their skills, and at their understanding of school subjects, thereby allowing them to become aware of their progress and to improve their relation with knowledge. This is particular the case because depending on the learner's self-efficacy beliefs about performing a task or learning a discipline, his/her motivation may vary and, consequently, he/she may be involved at different levels in his/her school work (Denoncourt et al. 2004).
Nevertheless, success in thinking at a meta level, that is, reflecting on one's own cognition, is not innate. It requires the acquisition of specific strategies (Weil et al. 2013), and intervention on the part of the teacher can support students in the development of these strategies. However, it appears that few teachers take metacognition into account in their instructional practices (Lafortune \& Fennema 2013); on the one hand, they do not always see the direct added value it can bring, and on the other hand, they are not necessarily trained in doing this.

This has led us to seek to identify the links between metacognitive mediation and students' self-efficacy belief for the performance of complex tasks. Our two research questions are as follows: to what extent can the use of metacognitive mediation influence (1) students' self-efficacy beliefs and (2) students' use of cognitive strategies in the context of complex tasks?

To answer these questions, we worked for three weeks with three classes of secondary 1 students who performed the same tasks in their human sciences classrooms, a discipline chosen for the fact that it requires students to be able to process information, reflect on the area studied and also reflect on their own approaches.

In the first class, activation of metacognition was initiated by the teacher (condition A), in the second class, activation of metacognition occurred between peers (condition B) and in the third class, there was no metacognitive mediation (condition C). Our goal is to compare the three conditions in terms of changes in students' self-efficacy belief related to task performance and their use of metacognitive strategies, through

\footnotetext{
a, ${ }^{*}$ Corresponding Author: Stéphane Colognesi, Faculty of Psychology and Educational Sciences, IPSY : Psychological Sciences Research Institute, Université catholique de Louvain, Louvain-la-Neuve, Belgium. E-mail: stephane.colognesi@uclouvain.be

Vanessa Hanin, Faculty of Psychology and Educational Sciences, IACHOS: Institute for the Analysis of Change in Contemporary and Historical Societies Université catholique de Louvain, Louvain-la-Neuve, Belgium. E-mail: Vanessa.hanin@uclouvain.be

c Alena Still, Faculty of Psychology and Educational Sciences, IPSY: Psychological Sciences Research Institute, Université catholique de Louvain, Louvain-laNeuve, Belgium. E-mail: Alena.still@uclouvain.be

${ }^{d}$ Catherine Van Nieuwenhoven, Faculty of Psychology and Educational Sciences, IACHOS: Institute for the Analysis of Change in Contemporary and Histor
} ical Societies, Université catholique de Louvain, Louvain-la-Neuve, Belgium. E-mail: catherine.vannieuwenhoven@uclouvain.be 
a pretest-posttest comparison among the 85 students who took part in the study. To nuance and refine the quantitative results obtained, we followed four students in each group where metacognition was used.

\section{Metacognition}

Currently, self-regulated learning is considered to be one of the fundamental concepts in education (Muijs et al. 2014). It is the individual's attempt to achieve the personal goals she has set for herself in relation to a task, by producing thoughts, actions and sensations to use in that attempt (Boekaerts 2002). Self-regulated learning has three dimensions: motivation, behavior and metacognition (Muijs et al. 2014; Noël \& Cartier 2016; Zimmerman 2008). Muijs et al. (2014) highlighted why self-regulated learning is necessary, but not sufficient, for learning and academic success, stressing that the role of metacognition is essential in this process, as it allows learners to monitor their levels of knowledge and skills, but also, among other things, to use their resources in the best possible way.

Desoete and Ozsoy (2009), accorging to Flavell (1979) explain that "the concept has been introduced to describe and explain how people gain control over their learning and thinking, particularly in the case of cognitive failures and difficulties they meet when dealing with information processing and problem solving" (p. 1)

There are three facets to metacognition : metacognitive knowledge, metacognitive experiences and metacognitive skills (Desoete \& Ozsoy, 2009; Efklides, 2001, 2008; Flavell, 1979). Flavell's (1979) early work defined metacognitive knowledge as knowledge and beliefs accumulated with experience and stored in long-term memory. Flavell (1979) distinguished three categories of declarative meta-knowledge: individual-related (ways of learning, strengths and weaknesses, skills, competencies, etc.); task-related (nature of the information to be processed and task requirements) and strategy-related (means to achieve the objective).

Metacognitive experiences refer to what a person becomes aware and feels when they discover a task and process the related information (Efklides, 2008). These may include metacognitive feelings, metacognitive judgments/estimates and knowledge about online tasks. What distinguishes metacognitive knowledge from metacognitive experiences is the kind of monitoring each involves. Metacognitive knowledge is related to offline monitoring of cognition, whereas metacognitive experiences represent online monitoring of cognition (Efklides 2008; Efklides et al. 2006).

Metacognitive skills refer " to the voluntary control people have over their own cognitive processes" (Desoete \& Ozsoy, 2009). Colognesi and Van Nieuwenhoven (2016), based on the work of Deschênes (1991), Veenman (Veenman 2012; Veenman et al. 2005) and Efklides (2008), identified six metacognitive skills; two for each of these phases of task completion. Before the task, the skills of orientation (thinking about the task and developing goals) and planning (identifying necessary strategies and planning steps) come into play. These two skills involve anticipation. During the task, the skills of verification (detecting execution errors) and regulation (modifying, correcting the approach) are needed. These two skills activate explanation of actions, critical distance, and self-questioning. After the task, the skills of evaluation (taking stock of what has been achieved) and self-regulation (reviewing the entire process and projecting yourself into another version of the task) are called for. These two skills generate explanation of its opinion and self-assessment.

Indeed, Veenman et al. (2005) and Veenman's (2012) work identified three points during which metacognition can be promoted in school situations: before, during and after an action, when students can be asked to express themselves in relation to what they think they will be doing (before), what they are doing and why (during), and what they think about their actions or what they would do in a next iteration of the task (after).

\section{Self-Efficacy Beliefs}

Self-efficacy beliefs are a component of a broader concept, the self-concept, defined as "the perception (knowledge) and assessment (judgment) that an individual has of his or her personal characteristics" (Paradis \& Vitaro 1992, as cited in Galand \& Gregoire, 2000, p. 3). Self-concept is a "global and relatively stable representation" (Desmette et al. 2001, p. 4) which varies from one person to another and, for the same person, from one field to another (Galand \& Grégoire 2000). Self-concept comprises self-efficacy beliefs, also called feelings of competence (Ahmed et al. 2012), that is, an individual's judgment of his/her personal ability to organize and execute a course of action in order to attain self-set goals (Bandura 1997). Two aspects should be noted: the feeling of effectiveness is specific to a task and/or a subject-matter (Galand \& Vanlede 2004/5) and includes the notion of likely success, which encourages a person to engage, or not, in a task.

In this regard, much research has focused on the relationship between self-efficacy beliefs and motivation in the school environment. Authors such as Galand and Vanlede (2004/5) and Perreault, Brassart and Dubus (2010) have shown that the learner's level of belief in her chances of success impacts her behavior and level of engagement in a task, as well as her actual performance. In addition, depending on the perception of her competence, the learner seeks to avoid a situation or activity perceived as threatening or, conversely, invests significantly if she believes in her chances of success (Perreault et al. 2010).

Similarly, a learner with strong self-efficacy beliefs perceives complex tasks as a challenge, sets challenging goals and invests more in their achievement. If the situation becomes more complex, the learner increases her efforts. On the other hand, a learner with low self-efficacy beliefs will tend to be less diligent and quickly give up, as her motivation is quite low. Although she has sufficient skills and abilities, she does not know how to use them and is influenced by her belief in her own abilities (Lecomte, 2004). In this way, self-efficacy beliefs play a significant role in the student's learning process.

A review of the literature (Bandura 1997; Conway \& Pleydell-Pearce 2000; Galand \& Vanlede 2004/5) shows that self-efficacy beliefs are developed through four sources of information: active mastery experiences (i.e., the influence of background, school history and past academic performance), vicarious experiences (i.e., being aware of others' success or failure in tasks can influence one's own self-efficacy beliefs, so that the perceived level of competence in others also influences the construction of one's self-efficacy beliefs), verbal persuasion (i.e., the impact of encouragement, words of support, or any other message given to the learner) and physiological and emotional states (Hanin, Grégoire, Mikolajczack, Fantini-Hauwel, \& Van Nieuwenhoven, 2017).

\section{Associations Between Self-Efficacy Beliefs and Metacognition}

The work of Schunk and Pajares (2015), Zimmerman (2008) and Cosnefroy (2010) has shown the link between self-efficacy beliefs and develop of metacognitive skills. The more the individual believes in her abilities, the more she uses effective strategies, engages in difficult tasks, makes efforts and spends time studying. From an iterative perspective, we have shown (Colognesi \& Van Nieuwenhoven 2016; Hanin \& Van Nieuwenhoven, 2018) that metacognition leads to positive modification of the learner's self-efficacy belief and to an increase in performance. Further, Perreault et al. (2010) also pointed out that the learner's metacognitive capacity, that is, the ability to reflect on his or her own approaches and on his/herself, pre- 
dicts how he or she will make a judgment about his skills. Thus, it seems that metacognition and self-efficacy beliefs interact with each other. The question is whether the implementation of metacognitive mediation influences self-efficacy beliefs.

\section{Method}

The present study pursues a dual objective. First, we sought to characterize the impact of three modalities of metacognitive mediation on first-year secondary students' self-efficacy beliefs. Second, we would like to know if the nature and number of cognitive strategies used by the students evolve differently if the metacognitive questions are asked by the teacher (condition A) or by peers in a subgroup (condition B), as compared to a condition without metacognitive prompting (condition C).

To carry out this study, we have chosen to combine quantitative and qualitative analysis, thus opting for a mixed-method approach that combines two axes: quantitative analysis that establishes links between various variables through the use of empirical data, together with qualitative analysis that focuses more on understanding the relationships between those variables (Creswell \& Plano Clark 2007).

\section{Sample}

Our sample consisted of six first-year secondary classes (two classes per condition) from the same school in Brussels, French-speaking Belgium. The characteristics of the participants in the three conditions are presented in Table 1. In condition $A$, it was the teacher who enacted metacognitive mediation, in condition $B$, it occurred between peers and in condition $C$, there was no metacognitive prompting.

Table 1. Information on the sample

\begin{tabular}{cccccc}
\hline Item & Total & Girls & Boys & M age (SD) & Results (/20) \\
\hline Condition A & 26 & 17 & 9 & $12.4(0.71)$ & 11.3 \\
\hline Condition B & 32 & 15 & 17 & $12.1(0.42)$ & 12.6 \\
\hline Condition C & 27 & 15 & 12 & $12.5(0.64)$ & 12.5 \\
\hline $\begin{array}{l}\text { Note. Result }=\text { Average score in Human Sciences on the report card issued prior to the } \\
\text { intervention }\end{array}$
\end{tabular}

To be able to analyze in detail how students respond to metacognitive mediation, we followed four randomly selected students each in conditions A and B, throughout the intervention.

\section{The Intervention}

For three weeks, the six classes experienced a course sequence aimed at working on "food over time", and more precisely, during four major periods of history. The two main objectives of the sessions were: formulating a research question and selecting information through the study of how people eat over time. A schematization of the whole course sequence is proposed in Figure 1.
The first task took place without prior instruction to allow the teacher to identify the students' initial representations. $2 \times 50$ minutes were spent on each task, as well as on the intermediate lessons. Three progressive and complex tasks were assigned to the students as they went along, based on using a complete collection of paper documents provided by the teacher. Using these documents, the three tasks were to complete a summary table, make a mind map and write a summary tracing the evolution of food over time (progressive development in what humans had available/ used as food).. The tasks and activities were identical in all six classes, which were taught by the same teacher. The only variable was the introduction or not of the metacognitive intervention, and the agent by whom metacognition was introduced (by the teacher or between peers).

\section{Metacognitive Mediation}

Table 2 presents the metacognitive intervention (Colognesi \& Lucchini, 2016; Colognesi \& Van Nieuwenhoven, 2016, 2017) enacted in conditions $A$ and $B$. In practice, in condition $A$, metacognitive mediation went through the teacher; some students answered questions orally, while others benefited from the responses of others. In condition $B$, following the work of Gagnière, Bétrancourt, and Détienne (2007), the allo-confrontation technique was applied; namely, students explained to each other, without interaction with the teacher, the aspects prompted by the questions presented on the board. Students share in pairs there had some groups of three if there was an odd number of students. In both conditions, metacognitive mediation was repeated at three time points: before, during and after the task.

Table 2. Metacognitive intervention performed in each experimental condition

\begin{tabular}{|c|c|c|}
\hline Point time & $\begin{array}{l}\text { Metacognitive inter- } \\
\text { vention in condition A: } \\
\text { questions are asked by } \\
\text { the teacher and students } \\
\text { answer in large groups }\end{array}$ & $\begin{array}{l}\text { Metacognitive intervention } \\
\text { in condition B: questions } \\
\text { are recorded on the board, } \\
\text { and students share in } \\
\text { pairs (students grouped } \\
\text { themselves), without the } \\
\text { teacher's involvement }\end{array}$ \\
\hline $\begin{array}{l}\text { Before the } \\
\text { task is } \\
\text { completed }\end{array}$ & $\begin{array}{l}\text { Can you explain the } \\
\text { instructions again in your } \\
\text { own words? } \\
\text { How do you plan to carry } \\
\text { out the task? }\end{array}$ & $\begin{array}{l}\text { Explain the instructions and } \\
\text { share strategies that could } \\
\text { be used to achieve the task. }\end{array}$ \\
\hline $\begin{array}{l}\text { During the } \\
\text { task }\end{array}$ & $\begin{array}{l}\text { What are the difficulties } \\
\text { you are facing? } \\
\text { What strategies do you } \\
\text { use to move the task } \\
\text { forward? }\end{array}$ & $\begin{array}{l}\text { Explain the difficulties } \\
\text { encountered and the strate- } \\
\text { gies used to overcome them } \\
\text { or to progress in the task. }\end{array}$ \\
\hline $\begin{array}{l}\text { After the } \\
\text { task is } \\
\text { completed }\end{array}$ & $\begin{array}{l}\text { Next time, what could you } \\
\text { do to be more effective? }\end{array}$ & $\begin{array}{l}\text { Explain your opinion of your } \\
\text { product. } \\
\text { Explain what can be put in } \\
\text { place next time to be more } \\
\text { effective. }\end{array}$ \\
\hline
\end{tabular}

As a reminder, in condition $C$, the "metacognition" variable was neutralized, so that students had no metacognitive intervention at any time.

\begin{tabular}{|c|c|c|c|c|c|c|c|c|}
\hline Metacognition & Condition & & Task 1 & Lesson & Task 2 & Lesson & Task 3 & \\
\hline $\begin{array}{l}\text { Questions asked by } \\
\text { the teacher }\end{array}$ & A & & & A & & $\hat{\mathbf{a}}$ & & \\
\hline $\begin{array}{l}\text { Questions asked } \\
\text { between peers }\end{array}$ & B & & & & & & & \\
\hline $\begin{array}{l}\text { No metacognitive } \\
\text { intervention } \\
\text { (Control Group) }\end{array}$ & c & 苞 & & & & & & 荘 \\
\hline & & & 3 week & $\nabla$ & & $\nabla$ & & \\
\hline
\end{tabular}

Figure 1. Schematic representation of the intervention 
The intervention presented in Table 2 was further developed for all four students to collect additional data. The aim was to be able to understand how students in the "metacognition" condition groups felt about the intervention, to have their opinions on how it was going, their difficulties, etc. During classtime, the researcher sat next to each of them to gather his information in the form of a discussion. All the data collected by audiorecording were transcribed.

\section{Measures and Data Processing}

\section{Self-efficacy beliefs}

For the mixed-method approach mentioned above, two data collection instruments were used: a questionnaire and specific qualitative follow-up with eight students in the two experimental conditions. We adapted Boekaerts' (2002) Online Motivation Questionnaire to assess students'self-efficacy beliefs. It includes 14 items that refer to three facets of self-efficacy belief, as shown in Table 3. Students were asked to rate their level of agreement for each item on a Likert scale ranging from 0 (strongly disagree) to 3 (strongly agree). The questionnaire was administered before (pretest) and after (posttest) the intervention (see Figure 1), and was read aloud by the teacher, who emphasized that this questionnaire does not seek to evaluate students' work or to judge how they perceive the human sciences course, but rather to determine to what extent they feel competent, or not, in this discipline. The internal consistency was very good (Time 1: $\alpha=.87$, Time $2: \alpha=.84$ ).

\section{Cognitive strategies}

We added an additional question to the questionnaire (item 15), aimed at measuring the strategies that students can explain when asked about the performance of complex tasks in the human sciences course. It is an open-ended item having three sub-questions : (1) when I have a task to perform in human sciences, I proceed in such a way... ; (2) when I complete a task in human sciences, I... ; (3) when I perform a task in human sciences, I can use the following strategies... In order to characterize the evolution of the learner's explicit strategies, a count of the strategies identified by the students before and after the intervention in response to these three sub-questions was carried out in the three conditions.

\section{Metacognitive mediation}

A content analysis (Miles \& Huberman, 1994) was applied to the data collected through interviews with the 8 students (4 from group A and 4 others from group B). In addition, we also recorded and transcribed whole class conversations. A researcher was present for all classes in all classrooms.

Table 3. Questionnaire and reference concepts

\begin{tabular}{|c|c|c|}
\hline N & Items & Reference concepts \\
\hline 1 & I think I am competent. & Active mastery experiences \\
\hline 2 & I feel more competent than the other students in the class. & Vicarious experiences \\
\hline 3 & No matter what I do, there are things I will never understand in this course . & Active mastery experiences \\
\hline 4 & When I think about the course, I feel stressed/anxious. & Physiological states \\
\hline 5 & I know I can do well. & Active mastery experiences \\
\hline 6 & I am sure I understand the course material. & Active mastery experiences \\
\hline 7 & By studying, I will be ready for the exam. & Active mastery experiences \\
\hline 8 & I like this class. & Physiological states \\
\hline 9 & No matter what I think about the course, I am trying to get involved. & Active mastery experiences \\
\hline 10 & I believe I can do as well or even better than the other students in the class. & Vicarious experiences \\
\hline 11 & I think I have the facilities to succeed in this subject. & Active mastery experiences \\
\hline 12 & If I get to the bottom of the course, I know I can succeed. & Active mastery experiences \\
\hline 13 & I feel like I have the strategies to do well. & Active mastery experiences \\
\hline 14 & When I have human sciences class, I don't want to go. & Physiological states \\
\hline
\end{tabular}

\section{Main Results}

The main results are presented in two stages. First, the results regarding changes in students' self-efficacy beliefs in the three conditions are presented. Then come the results pertaining to changes in the number and nature of the cognitive strategies they used.

Regarding the quantitative approach it is worth mentioning that, prior to analysis, checks of the theoretical assumptions underlying analysis of variance were undertaken including normality, homogeneity of variance and independence. The report showed that the assumptions were met.

Comparison Between the Three Conditions in terms of Self-Efficacy Belief

\section{Quantitative approach}

Descriptive statistics are available in the Appendix. In order to check for any baseline difference at pretest between the three groups, a univariate ANOVA was performed for the variables under consideration $(F(2,82)=2.27, p=.11)$.

The results of the repeated measures ANOVA show a significant difference in changes in self-efficacy belief between the three groups $\left(F(2,82)=36.85, p<.001, \eta^{2}=0.47\right)$. As seen in Figure 2 , the two experimental conditions show an increase in their self-efficacy belief between the beginning and the end of the intervention. This suggests that activation of metacognition, no matter how it is initiated, improved students' self-efficacy beliefs. Nonetheless, Bonferroni post-hoc tests highlighted no significant differences between the three conditions.

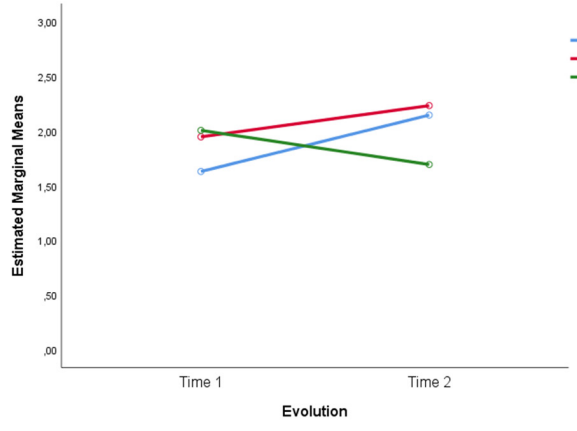

Figure 2. Mean self-efficacy belief over time by condition

Let us deepen this analysis by looking at the change within each group separately. A significant increase in self-efficacy belief between Time 1 and Time 2 was evident in condition 
A, where activation of metacognition was introduced by the teacher $(t(25)=-6.43, p<.001)$, as well as in condition $B$, where activation of metacognition was introduced by peers $(t(31)=-4.15, p<.001)$. In contrast, condition C, without metacognitive prompting, displayed a significant decrease in self-efficacy belief between the two measurement times $(t(26)=5.78, p<.001)$. This suggests that activation of metacognition, no matter how it was initiated, improved students' self-efficacy belief in this context.

Let us refine and complete these initial observations by consideration of the verbatim comments collected from the four students in conditions A and B.

Qualitative approach

The analysis of the data collected from students made it possible to highlight particular functioning in classes with conditions $\mathrm{A}$ and $\mathrm{B}$.

In condition A, when students were asked whether they were satisfied with their work, students mainly talked about care, writing and readability. The appearance of their work therefore seemed to them to be an important indicator of success (in the quoted material, RES indicates the researcher).

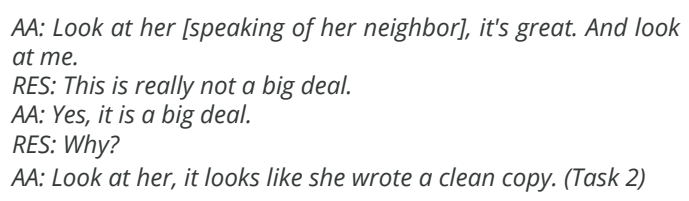

Another indicator of success that emerged from our analyses was the amount of information that students say they have written.. When a student made little progress, we see that his self-efficacy belief was weak.

RES: So JE, everything's fine? What have you already done? $A A$ : I haven't done anything yet.

RES: Nothing at all? There's nothing on your sheet?

$A A$ : Yes, there is.

RES: What have you already written?

$A A$ : Consumption. It's the only word that's written. And that's not much.

RES: Well, keep going then.

$A A$ : And if it's not much, it means that I'm not good. (Task 2)

Finally, it was exchanges with the teacher that led the student to be sure of himself.

RES: And you're sure that's a good way to do it? $A B$ : Yeah. Well, we talked about it yesterday. I explained how I was going to do it. Madam said it was a good idea. (Task 2)

In condition B, it seemed that students' self-efficacy belief differed from one student to another. One student expressed that he had no difficulty, contrary to reality. Reading his remarks, one gets the impression that he is not necessarily aware of it and this was the case throughout the intervention.

Well, I don't know... I don't have any difficulties. (BA, Task 1) Uh... well, I don't actually have one. What about you? (BA, Task 3)

On the contrary, another student showed more fragile self-efficacy belief and expressed herself largely about the obstacles encountered, with, as we can read, a willingness to complete the tasks correctly.

The difficulties I encountered were... the difficulty of putting all the information in the same place. (BB, Task 2)

My difficulty is time. I don't have enough time because I write more than I expected. (BB, Task 2)
The last two students appeared to have a self-efficacy belief that gradually improved over the course of the tasks.

Well, I still have trouble finding stuff in documents. (BC, Task 1)
I could do it, but I'm lazy to look (laughs). I don't know, there are times I can't find it. (BD, Task 1)

My difficulty is that when I had to write texts, they are too long. [silence and laughter] The texts were too long and as we should not produce too long texts, I have difficulty shortening them. (BC, Task 2)

Well, I don't have any difficulties because we noticed everything last time and I just have to reduce the sentences a little and write them down. (BC, Task 3)

Comparison Between the Three Conditions in terms of Metacognitive Behavior

\section{Quantitative approach}

Descriptive statistics concerning cognitive strategies are available in the Appendix. There were no baseline differences between the three conditions $(F(2,82)=1.28, p=.29)$.

The results of the repeated measures ANOVA showed a significant difference in changes in number of cognitive strategies between the three conditions $(F(2,82)=22.48, p<$ $\left..001, \eta^{2}=0.35\right)$. Figure $A$ highlights an increase for condition $\mathrm{B}$, consistency for condition A and a decline for condition C.

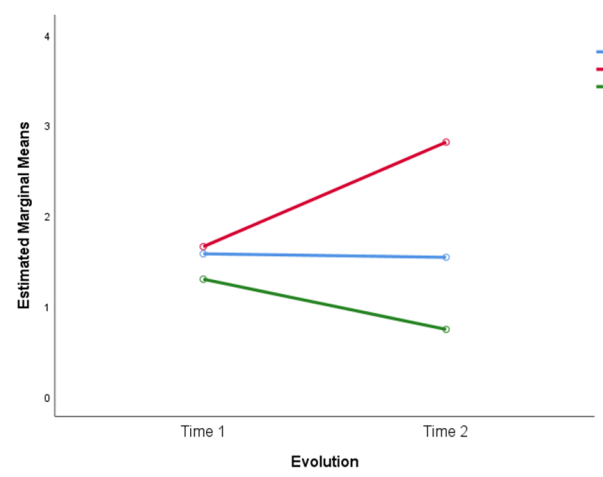

Figure 3. Mean cognitive strategies used over time by condition

Bonferroni's post-hoc tests make it possible to refine these observations. The two experimental conditions distinguished themselves significantly, to their advantage, from condition C (condition A: $M D=.54, p=.003$; condition $\mathrm{B}: M D=$ $1.22, p<.001)$. Further, condition $B$, where metacognition was prompted by peers, presents a significantly higher increase than that observed in condition $A$, where metacognition was prompted by the teacher $(M D=-.68, p<.001)$.

Let us refine these initial results by looking at the changes within each condition. Results indicate that condition A showed no significant increase between Time 1 and Time $2(t(25)=.21, p=.83)$, unlike condition $B$, which displayed a significant increase in the number of cognitive strategies used between the two measurement times $(t(31)=-6.05, p<$ $.001)$. Condition $C$ showed a significant decrease in the use of cognitive strategies between the beginning and the end of the intervention $(t(26)=2.85, p=.008)$.

Let us further refine and complete these initial observations by consideration of the verbatim comments collected from students.

\section{Qualitative approach}

First, we analyzed and compared the nature of the exchanges in the two experimental conditions (for the whole class). In condition A, some students answered the teacher while 
others listened. While more and more students asked for the floor to answer questions throughout the intervention, only volunteers were interviewed by the teacher. It was therefore not possible to ensure that every student had a chance to reflect on the presented prompts, and was also able to verbalize his comments. However, the data show that in condition A, the teacher pushed the student who expressed himself to go further in his answers and in his self-questioning, as as illustrated in the following emblematic extract. Jeremiah, the student, spoke during the whole-class discussion, and the teacher is asking these questions in front of everyone.

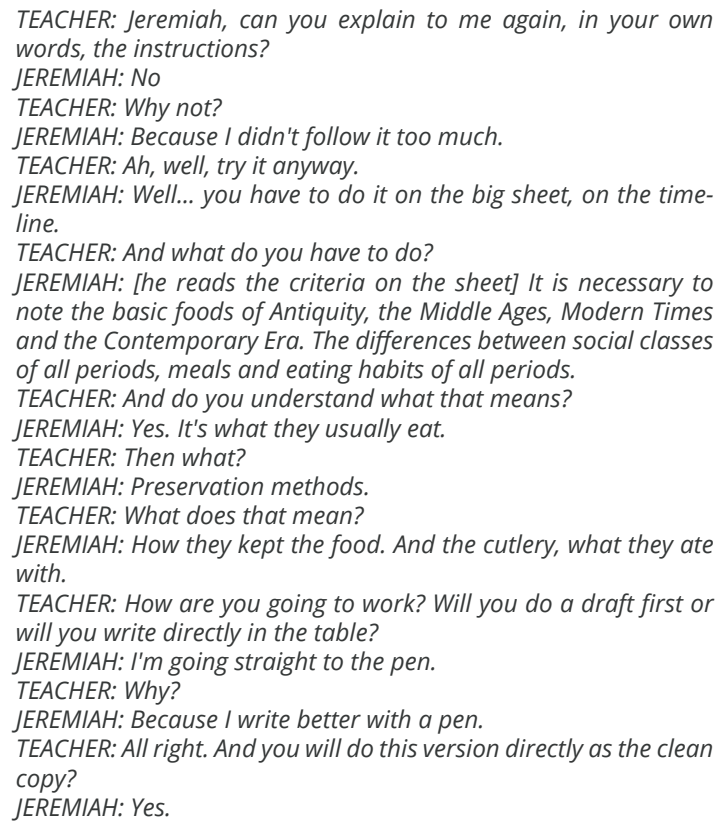

Further, we can see that in condition A the teacher was trying to make the students specify the different stages through which they thinks they are going, and pushed them to mention aspects relating to self-regulation, as shown in the following extract:

TEACHER: Yes, Erika, can you explain how you work?

ERIKA: First I make a draft. Then after that, I'll put it clean on the sheet.

TEACHER: All right. How do you do it?

ERIKA: I put as I go along what I read in the documents. (...)

TEACHER: So, for the next time you have the same task, are you going to do it the same way?

ERIKA: No, I won't make such an elaborate draft. I think I'm wasting too much time.

TEACHER: How will you do it, then?

ERIKA: I think I'll make a draft, but not with that much. I will put words and then make sentences by myself.

In contrast to condition $\mathrm{A}$, in condition $\mathrm{B}$, all the students were given the opportunity to express themselves. Thus, even if they did not have, like the teacher, the idea of further reflection and verbalization, students questioned themselves by following the prompts presented on the board. So they all had to talk and give an answer:

l: Well, what strategies do you use?

$\mathrm{N}$ : I highlighted the text in full color, and then I put keywords, with what was important. What about you?

I: The same as you, but I put highlighting in the text and I grouped everything I highlighted so as not to make too big texts.

We also see in students' discussions that they explained how they manage to accomplish the task, and to verify their work:

N: How do you know if it is good?

J: Well, you see in the documents, it says Middle Ages and so on, and then sometimes, in the documents, it is written in bold and I look first at what is written in bold to see if it is details.
In sum, even if peers were as competent at getting a friend to think about his or her strategies, they did so less thoroughly than the teacher.

In addition, the analysis of the verbatim comments of the students in condition B highlights an aspect that seems interesting to us: these students were concerned about who would listen to the recordings and what they would be used for. Despite the fact that this procedure was explained at the beginning of the process (that only the researcher would have access to the comments), the students asked the teacher several times about this subject (Madam, who will listen to what we say?). This suggests that students also appreciate sharing just among themselves about the difficulties and strategies they use, without the teacher's control.

What about the four students followed in each class? In this respect, the analysis shows that the students in condition A did not easily find the words to express themselves and answered several times, "I don't know", or rather vague strategies, such as "I read and searched" (AA, Task 1), "I read everything and found the words" (AA, Task 1), "I will read the document" (AC Task 1). The fourth student differed from the others, because this student managed to highlight the difficulty of the exercises, in particular the difficulty of being able to select the essential information, and then nuanced his/her remarks by explaining that once the task is launched, it then seems less complex. This student also manage to put words to the strategies mobilized:

I think I'm going to make a draft, but not with so many things. I will put words and then make sentences by myself. (AB, Task 1)

"Well, I'm not going to put all the information in, so as not to waste too much time. And so I'm going to surround the information instead. (AB, Task 2)

On the contrary, in condition B, the four students easily explained to the researcher concrete strategies implemented to complete the tasks, certainly because they had done it with their peers throughout the intervention.

I first highlight the important elements of the documents before I start working. (BA, Task 1)

I first read all the documents and then I look for all the little details in them. And I bring them together to make a nice sentence. ( $B B$ Task 1).

I read all the documents. Because I didn't read everything there. (BD, Task 1)

Second, we conducted a content analysis of the students' comments to item 15 in order to have a more fine-grained understanding of the difference identified between the two experimental conditions. It follows that, in condition A, the strategies mentioned by the students before and after the intervention were on the order of "document review" and "review the instructions". In the posttest, only two new items appeared: the "rereading of answers", proposed by six students, and the "creation of a table or mind map", mentioned by eight students. In condition $B$, the strategies at the beginning of the intervention were: "questions/considerations review", "drafting a draft", "highlighting keywords in documents", "writing a summary of what has been understood". In the posttest, though these same strategies were still present, another category appeared massively in students' responses, that of verification: "verify if the answer corresponds to the instructions", "verify the accuracy of the information", "verify if the answers are possible", "verify by using bold words", and so forth. The verification strategy was not mentioned by the students in condition A. This leads us to hypothesize that the metacognition generated by mediation between peers played a role in this development and that the exchanges confined between students encouraged them to exchange more freely about strategies for verifying their responses (related to the previous verbatim 
comment where the student asks the other what he/she does to know if it is good). In addition, in condition C, where there was no metacognitive intervention, the vast majority of learners mentioned "document and instructions review" as a strategy used, both before and after the intervention. However, although the strategies were almost identical at the two measurement times, the students' responses on the posttest are shorter, less elaborate than at the pretest. Therefore, we wonder if not having any metacognitive prompting during the three tasks could have influenced this behavior. Indeed, the fact that there was no prompting for students to analyze their functioning means that they may not have been stimulated to develop complete answers and reflect on their approaches.

In conclusion, on the basis of the verbatim comments collected throughout the intervention and the content analysis carried out for item 15, there appear to be common characteristics within the four students for conditions A and B. In addition to that, it should be noted, that differences appear between conditions $A$ and $B$ for one student. This student is a student with difficulties. In condition $A$ he was more efficient in answering the researcher's questions. The hypothesis is that since he has difficulty expressing the strategies he mobilizes, he needs the teacher's specific questions to do so.

\section{Conclusion}

Through a mixed-method approach, combining quantitative and qualitative analysis, this work aimed to study the extent to which metacognitive mediation influences the self-efficacy beliefs of secondary I students in Human Sciences.

This study confirms, for our sample, the impact of metacognition on self-efficacy beliefs. Indeed, the quantitative results show that in classes where metacognition was introduced, self-efficacy beliefs improved, which was not the case in the classes where students did not receive a metacognitive intervention.

In addition, the comparison of classes "with metacognition" showed that regardless of the agent by whom it is activated (by the teacher or by peers), mediations metacognitive leads to a gain in aspects related to active mastery experiences and psychological states of self-efficacy. The difference between the two "with metacognition" conditions lies in the strategies available to students to succeed in the tasks. Thus, the study found that when metacognitive mediations are managed between students, they are able to discuss more strategies for successful tasks than when the teacher asks them, and that the precise difference is in terms of verification strategies.

One could therefore wonder if it was the fact of having discussed between themselves, in a more "confined" situation and without the teacher's perspective, that led to this modification in students' awareness of this strategy. Each student had the opportunity to express him/herself orally to a peer. In this case, the expert (the teacher) was not "present" in the exchange and could not lead the students to specify one or the other aspect or push them to verbalize more deeply about their functioning. This could be an interesting avenue for intervention and research: to encourage students to develop their metacognitive skills, both in explanation and in questioning.

There are limitations of this study to be identified, which make it possible to consider prospects for future research. First, we worked in just a few classes, which does not allow us to generalize the results or to value one approach over another. This study should be replicated by multiplying the number of classes in order to validate or qualify its contributions. Second, we worked on the basis of the question- naire and the verbatim comments collected. Another possible perspective is to be able to cross-reference these data with the students' results on each of the tasks. Third, we tested two separate approaches for encouraging metacognitive activation. It now seems interesting to consider what can be achieved by a "mixed" approach to metacognition in educational systems, that is, where prompts are provided by the teacher or by peers.

\section{References}

Ahmed, W., Minnaert, A., Kuyper, H., \& Van der Werf, G. (2012). Reciprocal relationships between math self-concept and math anxiety. Learning and Individual Differences, 22(3), 385-389.

Bandura, A. (1997). Self-efficacy: The exercise of control. New York, NY: W. H. Freeman and Company.

Boekaerts, M. (2002). Bringing about change in the classroom: Strengths and weaknesses of the self-regulated learning approach. Learning and Instruction, 12, 589-604.

Brown, A. L. (1987). Metacognition, executive control, self-regulation, and other more mysterious mechanisms. In F. E. Weinert \& R. H. Kluwe (Eds.), Metacognition, motivation, and understanding (pp. 65-116). Hillsdale, NJ: Lawrence Erlbaum.

Colognesi, S., \& Lucchini, S. (2016). Le rapport à l'écrit des élèves : focalisation sur la dimension métascripturale [Students' relationship to writing: focusing on the metascriptural dimension]. Nouveaux cahiers de la recherche en éducation, 19(2), 33-52. https://doi. org/10.7202/1042848ar

Colognesi, S., \& Van Nieuwenhoven, C. (2016). La métacognition comme tremplin pour l'apprentissage de l'écriture [Metacognition as a springboard for learning to write]. In S. Cartier et B. Noël (Eds.), De la métacognition à l'apprentissage autorégulé [From metacognition to self-regulated learning]. (pp. 111 126). Bruxelles : De Boeck Supérieur.

Colognesi, S., \& Van Nieuwenhoven, C. (2017). Développer des habiletés de relecture critique des productions des pairs [Develop skills in peer review of written productions]. Education \& Formation, e-307(02), 7-25.

Conway, M. A., \& Pleydell-Pearce, C. W. (2000). The construction of autobiographical memories in the self-memory system. Psychological Review, 107, 261-288.

Cosnefroy, L. (2010). L'apprentissage autorégulé [Self-regulated learning]. Paris: L'Harmattan.

Creemers, B. P. M. (1999). The effective teacher: What changes and remains. Asia-Pacific Journal of Teacher Education and Development, 2, 51-64.

Creswell, J., \& Plano Clark, V. (2007). Designing and conducting mixed methods research. Thousand Oaks, CA: Sage.

Denoncourt, I., Bouffard, T., Dubois, V., \& Mc Intyre, M. (2004). Relations entre les facteurs du profil motivationnel d'élèves de sixième année du primaire et leurs anticipations envers le secondaire [Relationships between the motivational profile factors of grade 6 elementary school students and their expectations of high school]. Revue des Sciences de l'Éducation, 30(1), 71-89.

Deschênes, A-J. (1991). Les métaconnaissances [Meta-knowledge]. Montréal, Québec: Télé-Université. 
Desmette, D., Jaminon, C., \& Herman, G. (2001). Le sentiment d'efficacité personnelle de chômeurs en formation, un construct dynamique? [The feeling of personal efficiency of unemployed people in training, a dynamic construct?]. Revue Européenne de Psychologie Appliquée, 51(3), 217-228.

Desoete, A., \& Özsoy, G. (2017). Introduction: Metacognition, more than the lognes monster. International Electronic Journal Of Elementary Education, 2(1), 1-6.

Efklides, A. (2001). Metacognitive experiences in problem solving: Metacognition, motivation, and self-regulation. In A. Efklides, J. Kuhl, \& R. M. Sorrentino (Eds.), Trends and prospects in motivation research (pp. 297-323). Dordrecht, the Netherlands: Kluwer.

Efklides, A. (2008). Metacognition: Defining its facets and levels of functioning in relation to self- and co-regulation. European Psychologist, 13, 277-287.

Efklides, A., Kourkoulou, A., Mitsiou, F., \& Ziliaskopoulou, D. (2006). Metacognitive knowledge of effort, personality factors, and mood state: Their relationships with effort-related metacognitive experiences. Metacognition and Learning, 1(1), 33-49.

Flavell, J. (1979). Metacognition and cognitive monitoring: A new area of cognitive developmental inquiry. American Psychologist, 34, 906-911.

Gagnière, L., Bétrancourt, M., \& Détienne, F. (2007). La méthode d'allo-confrontation comme incitation métacognitive dans des situations d'apprentissage.[ The allo-confrontation method as a metacognitive incentive in learning situations] In C. Chauvin \& A. Tricot (Eds.) Actes des 4èmes journées d'étude en Psychologie Ergonomique EPIQUE 2007 (pp. 27-33). Nantes: Université de Nantes.

Galand, B., \& Grégoire, J. (2000). L'impact des pratiques scolaires d'évaluation sur les motivations et le concept de soi [The impact of school assessment practices on motivation and self-concept]. L'Orientation Scolaire et Professionnelle, 29(3), 431-452.

Galand, B., \& Vanlede, M. (2004/5). Le sentiment d'efficacité personnelle dans l'apprentissage et la formation : quel rôle joue-t-il ? D'où vient-il ? Comment intervenir ? [The impact of school assessment practices on motivation and self-concept] Savoirs, Hors série, 91-116.

Hanin, V., Grégoire, J., Mikolajczack, M., Fantini-Hauwel, C., \& Van Nieuwenhoven, C. (2017). Children's Emotion Regulation Scale in Mathematics (CERS-M): Development and Validation of a Self-Reported Instrument. Psychology, 8, 2240-2275.

Hanin, V., \& Van Nieuwenhoven, C. (2018). Évaluation d'un dispositif d'enseignement- apprentissage en résolution de problèmes mathématiques: Évolution des comportements cognitifs, métacognitifs, motivationnels et émotionnels d'un résolveur novice et expert [Evaluation of a teaching and learning system in mathematical problem solving: Evolution of cognitive, metacognitive, motivational and emotional behaviours of a novice and expert solver]. Évaluer. Journal international de recherche en éducation et formation, 4(1), 37-66.

Hattie, J. A. C. (2009). Visible learning: A synthesis of over 800 meta-analyses relating to achievement. London, UK: Routledge.
Kauffman, D. F. (2004). Self-regulated learning in web-based environments: Instructional tools designed to facilitate cognitive strategy use, metacognitive processing and motivational beliefs. Journal of Educational Computing Research, 30, 139-161.

Ko, J., Sammons, P., \& Bakkum, L. (2014). Effective teaching: A review of research and evidence. Hong Kong: Hong Kong Institute of Education and Reading, UK: CfBT Education Trust.

Lafortune, L., \& Fennema, E. (2003). Croyances pratiques dans l'enseignement des mathématiques [Practical beliefs in mathematics education]. In L. Lafortune, C. Deaudelin, P. A. Doudin, \& D. Martin (Eds.), Conceptions, croyances et représentations en maths, sciences et technos [Concepts, beliefs and representations in math, science and technology] (pp. 29-57). Sainte-Foy, Québec: Presses de l'Université du Québec.

Lafortune, L., Mongeau, P., Daniel, M. F., \& Pallascio, R. (2000). Approche philosophique des mathématiques et affectivité: premières mesures. [Philosophical approach to mathematics and affectivity: first steps] In R. Pallascio \& L. Lafortune (Eds.), Pour une pensée réflexive en éducation [For reflective thinking in education] (pp. 181208). Sainte-Foy, Québec: Presses de l'Université du Québec.

Lecomte, J. (2004). Les applications du sentiment d'efficacité personnelle [The applications of the feeling of self-efficacy]. Savoirs, 5, 59-90.

Miles, M. \& Huberman, A. (1994). Qualitative Date Analysis. Thousand Oaks, CA: Sage Publications.

Muijs, D., Kyriakides, L., van der Werf, G., Creemers, B., Timperley, H., \& Earl, L. (2014). State of the art - teacher effectiveness and professional learning. School Effectiveness and School Improvement, 25(2), 231-256.

Noël, B. (1997). La métacognition. Bruxelles: De Boeck.

Noël, B., \& Cartier, S. (2016). De la métacognition à l'apprentissage autorégulé [From metacognition to self-regulated learning]. Bruxelles: De Boeck.

Paradis, R. \& Vitaro, F. (1992). Définition et mesure du concept de soi chez les enfants en difficulté d'adaptation sociale: une recension critique des écrits [Definition and measurement of the concept of self in children with social adjustment difficulties: a critical review of the literature]. Revue Canadienne de Psycho- Education, 21, 93-114.

Perreault, B., Brassart, D. G. \& Dubus, A. (2010). Le sentiment d'efficacité personnelle comme indicateur de l'efficacité d'une formation. Une application à l'évaluation de la formation des enseignants [The feeling of self-efficacy as an indicator of the effectiveness of a training program. An application to the evaluation of teacher education]. In Actes du congrès de l'Actualité de la recherche en éducation et en formation (AREF) (pp. 1-8). Genève: Université de Genève.

Scheerens, J. (2008). Review of research on school and instructional effectiveness. Netherlands: University of Twente.

Schunk, D. H., \& Pajares, F. (2009). Self-efficacy theory. In K. Wentzel \& A. Wigfield (Eds.), Handbook of motivation at school (pp. 35-54). New York, NY: Taylor Francis. 
Veenman M. (2012). Metacognition in science education: Definitions, constituents, and their intricate relation with cognition. In A. Zohar \& Y. J. Dori (Eds.), Metacognition in science education - Trends in current research (pp. 21-36). London: Springer.

Veenman, M., Van Hout Wouters, B., \& Afflerbach, P. (2005). Metacognition and learning: conceptual and methodological considerations. Metacognition and Learning, 1, 3-14. doi: 10.1007.s11409-0066893-0

Weil, L., Flemming, S., Dumontheil, I., Kilford, E., Weil, R., Rees, G., .... \& Blakemore, S. J. (2013). The development of metacognitive ability in adolescence. Consciousness and Cognition, 22, 264-271.

Zimmerman, B. J. (2008). Investigating self-regulation and motivation: Historical background, methodological developments, and future prospects. American Educational Research Journal, 45(1), 166-183. 


\section{Appendix}

Mean and standard deviations for the two variables under study for the three conditions

\begin{tabular}{ccccccccc}
\hline & & & \multicolumn{2}{c}{ Condition $\mathrm{A}(\mathrm{N}=26)$} & \multicolumn{2}{c}{ Condition B(N=32) } & \multicolumn{2}{c}{ Condition C(N=27) } \\
\cline { 3 - 9 } & \multirow{2}{*}{ Min } & Max & Time 1 & Time 2 & Time 1 & Time 2 & Time 1 & Time 2 \\
\cline { 3 - 9 } & & & $\mathrm{M}(\mathrm{SD})$ & $\mathrm{M}(\mathrm{SD})$ & $\mathrm{M}(\mathrm{SD})$ & $\mathrm{M}(\mathrm{SD})$ & $\mathrm{M}(\mathrm{SD})$ & $\mathrm{M}(\mathrm{SD})$ \\
\hline Self-efficacy belief & 0 & 3 & $1.63(.53)$ & $2.15(.36)$ & $1.95(.52)$ & $2.23(.46)$ & $1.88(.59)$ & $1.69(.48)$ \\
\hline Cognitive strategies & 0 & 4 & $1.58(.50)$ & $1.54(.65)$ & $1.66(.90)$ & $2.81(.74)$ & $1.30(1.11)$ & $.74(.45)$ \\
\hline
\end{tabular}

